\title{
Engineering Cardiovascular Regeneration
}

\author{
Ingra Vollert ${ }^{1,2,3} \cdot$ Alexandra Eder ${ }^{1,2,3} \cdot$ Arne Hansen ${ }^{1,2,3} \cdot$ Thomas Eschenhagen $^{1,2,3}$
}

Published online: 3 April 2015

(C) Springer International Publishing AG 2015

\begin{abstract}
The human heart has very limited regenerative capacity, making the loss of heart muscle tissue during myocardial infarction essentially irreversible. Regenerative medicine aims at promoting the formation of new functional heart muscle in an injured heart, either by stimulating myocyte proliferation, formation of myocytes from preexisting stem cells, direct reprogramming of fibroblasts into myocytes, or adding new muscle tissue from exogenous stem cell sources. Recent advances in stem cell research make these goals more realistic. This review provides a short overview about different approaches for cardiovascular regeneration, stem cell sources, and modes of application, focusing on current cardiac tissue engineering techniques and their way towards clinical application.
\end{abstract}

This article is part of the Topical Collection on Artificial Tissues

Ingra Vollert and Alexandra Eder contributed equally to this work.

Thomas Eschenhagen

t.eschenhagen@uke.de

Ingra Vollert

i.vollert@uke.de

Alexandra Eder

a.eder@uke.de

Arne Hansen

ar.hansen@uke.de

1 Department of Experimental Pharmacology and Toxicology, University Medical Center Hamburg-Eppendorf, Martinistrasse 52, 20246 Hamburg, Germany

2 Cardiovascular Research Center Hamburg, University Medical Center Hamburg-Eppendorf, Hamburg, Germany

3 DZHK (German Centre for Cardiovascular Research), Partner site Hamburg/Kiel/Lübeck, Hamburg, Germany
Keywords Cardiac tissue engineering $\cdot$ Engineered heart tissue $\cdot$ Pluripotent stem cells $\cdot$ Cardiac differentiation . Cardiac repair

\section{Introduction}

Myocardial infarction (MI) is one of the most frequent causes of morbidity and mortality worldwide. Modern medicine has improved prevention of MI and allowed for improved prognosis following a MI, but ischemic loss of myocardium has surpassed arterial hypertension as the most frequent cause of terminal heart failure [1]. Until the end of the twentieth century, cardiomyocytes in the adult mammalian heart were considered essentially postmitotic and unable to divide. This view was challenged by describing substantial rates of cardiomyocyte cell division and turnover [2] and with reports of the influx of bone marrow-derived cells with potential for cardiac transdifferentiation [3]. Today, 15 years later, though still controversial, most researchers would agree that (i) the turnover rate of the adult human (as well as murine) heart is less than $1 \%$ per year, i.e., that we die with a relevant fraction of cardiomyocytes as old as ourselves [4], (ii) the few new myocytes that develop during adulthood derive from resident cardiomyocytes by cell division rather than from a "resident cardiac stem cell" source [5] or bone marrow-derived cells, and (iii) the regeneration is too low to be clinically meaningful, i.e., current levels of regeneration are not able to rescue heart function after a large MI. Thus, patients experiencing a significant loss of muscle mass $(>1 / 3$ of the left ventricle) develop heart failure and have a poor prognosis [6]. Current treatment options include heart transplantation, which is limited due to organ donor shortage and implantation of mechanical assist devices. The latter therapy, though increasingly 
effective, is compromised by severe complications, and a 1year mortality rate of $20 \%$ [7]. Gene therapy of sarcoplasmic reticulum ATPase (CUPID trial [8, 9]; NCT01643330, NCT00534703) is currently being developed as a novel treatment option for patients with heart failure, but is unlikely to be effective in patients in whom a critical fraction of contractile mass is lost. These patients are the target population for regenerative approaches, i.e., attempts to add new contractile heart muscle mass to the failing heart. This review provides a brief overview of possible cell sources and then focuses on cardiac tissue engineering and regeneration using pluripotent stem cells. We refer interested readers to detailed reviews as indicated in each chapter, respectively.

\section{Cell Sources for Cardiac Regeneration}

Numerous cell types have been claimed to regenerate the mammalian heart, and the debate which cell type is optimal for cardiac regeneration remains open. The problem of this field is that one can find evidence for almost everything in the literature (including strictly opposing results and conclusions), making it difficult for interested readers to orient. The confusing situation has prompted the Federal Food and Drug Administration (FDA) to assemble a Guidance for Industry for the preclinical assessment of investigational cellular and gene therapy products [10]. The choice of cells for therapeutic interventions encompasses bone marrow mononuclear cells (BMC), mesenchymal stem cells (MSC), endothelial progenitor cells (EPC), adipose tissue-derived cells (ATC), resident cardiac stem cells, cardiospheres, embryonic stem cells (ESC), parthenogenetic stem cells (pSC), and induced pluripotent stem cells (iPSC; review in [11, 12]). Advantages of $\mathrm{BMC}$ that explain their fast and widespread clinical application in cardiology is their already established clinical use (for bone marrow transplantation in hematological indications), the autologous approach, simple access, and apparent lack of side effects. The main disadvantages are the lack of convincing evidence that $\mathrm{BMC}$ can form new cardiomyocytes [13, 14] and lack of clinically relevant effects [15]. Moreover, the concept of a "paracrine" mechanism of action, generally employed to explain positive effects on heart function in the absence of new myocardium, is controversial in light of the fact that BMC that are infused into the coronary circulation do not even remain in the myocardium for extended periods at a relevant rate [16]. This problem is less prominent when cells are injected into the myocardium, but still the retention rates are below $20 \%$ in $24 \mathrm{~h}$ [17]. The so-called EPC are very likely macrophages [18], and early claims of a cardiac transdifferentiation potential [19] have not been substantiated. Moreover, it is very likely that these cells, though promoting angiogenesis by a paracrine mechanism [20], do not directly form endothelial cells [21]. Thus, they may act in a manner originally proposed by Schaper's group, i.e., "do not promote vascular growth by promoting vessel walls, but may function as supporting cells." [22]. MSC are still being investigated for their capacity to regenerate cardiomyocytes [23], but the evidence remains controversial [24]. The capacity of c-kitpositive resident stem cells [25] to form new myocytes under normal and diseased conditions has been seriously challenged by a carefully conducted study using genetic targeting of the ckit locus [26]. A clinical study with these cells, originally published in The Lancet [27], raised concerns [28]. Socalled cardiospheres, originally described by Messina and colleagues [29] were also tested in an early clinical study [30], but evidence for true remuscularization is incomplete. Perinatal (e.g., placental, umbilical cord blood) and fetal (e.g., amniotic fluid) stem cells do not only have the disadvantage of ethical concerns, but evidence of full cardiac differentiation at relevant efficiency is lacking [31, 32]. Taken together, the problem of all non-pluripotent stem cell sources is their limited or absent potential to differentiate into cardiomyocytes. Since this is the key requisite for true regeneration, the following chapters of this review will focus on the potential of pluripotent stem cells to regenerate the heart and possible strategies to use this potential for therapy.

\section{Pluripotent Stem Cells}

Pluripotency describes the ability of a cell to differentiate into all cell types of the three germ layers (endoderm, ectoderm, mesoderm) and their derivations but not extraembryonic trophoblast, including retina cells [33], neuronal cells, embryonic erythrocytes, or cardiomyocytes among others (review in [34]).

\section{Embryonic Stem Cells}

Embryonic stem cells (ESC) are derived from the inner cell mass of blastocysts. Human ESC (hESC) were the first pluripotent stem cell source [35], and results of first clinical studies using $\mathrm{hESC}$ for regenerative repair in the eye have recently been reported [36, 37].

\section{Parthenogenetic Stem Cells}

Parthenogenesis occurs in some amphibians, fish and reptiles, and describes the unisexual reproduction of an organism. Once the oocyte is activated (e.g., by hormones), it starts to develop like a fertilized cell. Mammals do not show this phenomenon. However, parthenogenesis as an error of nature was identified as the cause of ovarian teratomas in the 1950s [38]; it is possible to experimentally induce parthenogenesis in mammal oocytes in vitro by chemicals, and parthenogenic stem cells (pSC) and their differentiated progeny have been 
successfully derived from the inner mass of pSC-derived blastocysts from mice [39] and humans [40].

\section{Induced Pluripotent Stem Cells}

Induced pluripotent stem cells (iPSC) are derived from somatic cells by introducing a combination of pluripotency factors [41], a seminal discovery that was awarded with the Nobel Prize to Yamanaka in 2012. Protocols to generate hiPSC from somatic cells are cell type-independent [42] and are based on the original protocol with lentivirus encoding for c-Myc, Klf4, Oct-4, and Sox-2 [41]. Since lentivirus randomly integrate into the host genome and may thereby activate or inactivate genes, many researchers worked on improving this method by using non-integrating viral transduction such as Sendai virus [43•], direct transfer of mRNA [44] or proteins [45], or replacing some of the pluripotency factors by small molecules [46, 47]. Given the relative ease and robustness and the lack of ethical concerns in their generation, human iPSC (hiPSC) are becoming increasingly important not only in the field of regeneration [48] but also as an unlimited source of patient/ disease-specific differentiated cells with great economic potential (e.g., Axiogenesis AG, Cellular Dynamics International, Pluriomics).

\section{Advantages and Disadvantages of the Different Pluripotent Cell Sources}

The use of hESCs raises ethical concerns $[49,50]$, but the debate is much quieter today than it was 10 years ago, mainly because the vast majority of researchers changed to hiPSCs which are widely available now and lack these concerns. Immunogenicity of the cell source is an important issue in clinical application. Conceptually, the use of ESCs or pSCs for regenerative purposes will be allogeneic and therefore, in principal, will require immune suppression. However, banks of a few hundred (ESC) or fewer (pSC) donor cell lines would suffice to achieve perfect HLA matching in most patients [51]. While HLA matching would not entirely preclude the need for immunosuppression due to the fact that there are many minor histocompatability antigens, it would lessen the need for full-level immunosuppression with its known toxicity. Together with optimized freezing and thawing protocols for the differentiated progeny (e.g., cardiomyocytes, see below), this would allow an off-the-shelf application. Autologous, (i.e., patient-derived) iPSCs should, at least in theory, allow an autologous approach without requiring immunosuppression, but recent studies suggest that even the use of autologous transplanted iPSCs may require immunosuppression $[52 \cdot, 53]$. A third issue, particularly relevant to hiPSC, is the potential for malignant transformation. C-myc is an oncogene and, as mentioned above, lentivirus integrate and could activate endogenous proto-oncogenes. New protocols without c- myc and using non-integrating vectors $[43 \cdot, 54]$ would minimize this risk. A general problem of cells cultured for extended periods is their genomic instability (e.g., potential for mutations and karyotype alterations [55]). These considerations do not prevent the clinical application of pluripotent stem cellderived products, but require that each single batch of ESC-, pSC-, or hiPSC-derived cell products undergo extensive quality control, an important hurdle for regulatory authorization [56].

\section{Cardiac Differentiation of Pluripotent Stem Cells}

Almost 30 years after the first report on cardiomyocyte differentiation from (murine) pluripotent stem cells [57], cardiac differentiation protocols have improved tremendously. In the early days, spontaneous differentiation resulted in such small numbers of cardiomyocytes [58] that cardiac replacement therapy (requiring an estimated $10^{8}$ to $10^{9}$ cardiomyocytes) seemed hardly a realistic option. Today, by applying lessons learned from cardiac development, it is possible to generate cardiomyocytes independently from the initial cell line with high efficacy and purity $[59 \bullet, 60,61,62 \cdot \bullet]$. Nevertheless, generating the quantities needed for a large scale study (e.g., phase 3 study) will be the next challenge. Human PSC can be differentiated into cardiomyocytes by various procedures. Most of the protocols (for hESC and hiPSC) are based on the sequential administration of signaling molecules such as activin A and BMP4 [63, 64] and cytokines along with inhibition of GSK $3 \beta$ (CHIR; $[59 \cdot, 61]$ ) or inducing and inhibiting the Wnt signaling pathway at different stages of differentiation. The concentration, ratio, and timing of these factors are of utmost importance and might depend on the starting cell line. Current methods for cardiac differentiation comprise the formation of embryoid bodies (EBs; [65]), 2D-culture (on Matrigel or Geltrex [59•,63, 66]), or the inductive coculture feeder cells (END-2 stromal cells; [67]) that secrete signaling molecules. Generation of embryoid bodies can be achieved using (i) the hanging drop method [58] that is very laborious and only feasible for small amounts of cells, (ii) forced aggregation in micro-cavities [68], which lead to EBs of uniform size and shape, but is also limited in terms of throughput, and (iii) suspension culture ([69]; own lab experience) that allows large scale production [70]. Most currently used protocols use direct differentiation of PSC in the monolayer format [59•, $62 \cdot \bullet$ that does not require the formation of EBs and thereby reduces the procedural steps. They are based on Matrigel [66] or feeder-cell coated vessels. The differentiation efficiency is highly depending on the timing, differentiation factors, and culture medium (review in [71]). By now, efficient protocols result in up to $90 \%$ pure cardiomyocytes without genetic selection (see above), demonstrating that differentiation is no longer a major bottleneck on the way to cardiac replacement therapy. Another important improvement was the 
identification of protocols allowing cryopreservation of the differentiated cells [72•]. These protocols facilitate the work with large cell numbers, which are required for cardiac repair in large animal models and ultimately in humans, and allow for quality control before application. A new cell stabilization technology at room temperature (e.g., Biomatrica) might reduce costs (e.g., storage and shipping) tremendously and smooth the way for a truly off the shelf product, but has not yet been tested with differentiated cardiomyocytes.

\section{Current State of Clinical Application with Pluripotent Stem Cells}

Clinical experiences with pluripotent stem cell therapy have recently been reported. A clinical trial in 18 patients with macular degeneration evaluated the primary endpoint safety and tolerability of hESC-derived retinal pigment epithelial cellbased therapy. In a follow-up period of 22 months, patients receiving $\mathrm{hESC}$-derived retinal pigment epithelial cells for therapy showed no unwanted cell proliferation of the graft or severe adverse events. Fifty-five percent of the eyes receiving transplantation of hESC-derived retinal pigment epithelial cells showed improved visual acuity, whereas the untreated fellow eyes did not [37]. Recently, a Japanese woman received autologous hiPSC-derived retinal pigment epithelial cells as therapy for her visual impairment [73]. The whole iPSC-community is now curiously looking at this case. If this first hiPSC-therapy proves safe, it will pave the way for other iPSC-based clinical applications including therapy of myocardial infarction.

\section{Approaches for the Use of Pluripotent Stem Cell Products in Cardiac Regeneration}

A straight forward approach for administration of cells for cardiac regeneration is to inject the cells directly into the infarcted myocardium. The Murry group in Seattle has been systematically investigating the effect of intramyocardial injection of human ESC-derived cardiomyocytes into rats [63, 74], guinea pigs [75], and pigtail macaques [62・•]. These studies report remuscularization in the infarct zone and intense vascularization of the grafts on the donor heart. The primatepublication nicely shows electromechanical coupling of the graft cells to the donor heart, but also describes the occurrence of arrhythmias in the macaques. Unfortunately, no data on functional effects were available in the primates, due to the small infarct size (2.5-10\%) and thus absence of an initial dysfunction and/or small numbers of treated animals. Since the time point of evaluation seems to have an underestimated impact on the apparent study success and functional improvements faded between 4 and 12 weeks after intervention (van Laake et al. [76] vs. Laflamme et al. [63]), larger studies with later endpoints are needed. Such studies also need to answer the question of effective cell dose, i.e., how many transplanted cells are minimally needed to repair the heart and improve function, an obvious question hardly addressed in the field. It is unlikely that such questions can be answered in nonhuman primates, both for ethical and economic reasons [77]. The minimal effective dose is of particular importance because injected cells have a low retention and survival rate (see above) and were accordingly found in the lung, liver, kidney, and spleen of the recipients [78]. This raises obvious safety concerns and indicates that low retention rates should not simply be overridden by injecting very large cell numbers. Instead, cells can be transplanted as 3D heart tissues that have been engineered in vitro (see below), microencapsulated, or suspended in hydrogels. The latter may be a simple solution to reduce cell apoptosis and enhance retention rate [79]; microencapsulation may further protect cells from immune defense and increase survival rate (review in [80]).

The MAGIC trial in 2008 [81] investigated the injection of autologous skeletal myoblasts in and around the scar after MI. The myoblast transfer did not improve regional or global LV function, but induced arrhythmias. The lack of LV function improvement is very likely related to the lack of coupling of skeletal myoblasts to host myocardium [82], but was also explained by the low retention rate of injected cells. Following this reasoning, the group around Menasché directly compared cell injections to placebo-suspension and freshly fibrinembedded cells or cells seeded on collagen sponges. Only the groups of rats which received patches (fibrin gel or collagen sponge) showed improved LV-function after myocardial infarction, arguing for the use of patches or preformed scaffolds in cardiac replacement therapy [83]. To address safety and efficacy questions of PSC-derived products, Menasché and colleagues investigated the transplantation of cell sheets containing adipose-tissue derived stroma cells combined with rhesus ESC-derived SSEA- $1^{+}$cardiac progenitors in a Rhesus monkey model [84]. No teratomas were found in the hearts of five recipient animals 2 months after implantation of the sheets, but similar to the other non-human primate study [62・•], functional data are lacking because the initial injury was too small (and animals did not survive larger infarcts). In a follow-up study, stem cell-derived cardiac progenitors were generated under clinical-grade conditions and injected into immunocompromised mice [85]. Whereas undifferentiated hESC induced teratoma formation, as expected, the cardiac progenitors did not. Additionally, this study re-confirmed that hESCderived cardiac progenitors embedded in a fibrin patch could increase LV function in a rat MI-model. The data paved the way for approval by the French regulatory authorities for the first human clinical trial using this method [85] and treatment of the first patient in October 2014 (http://medicalxpress.com/ news/2015-01-recipient-stem-cell-treatment-doctor.html).

The most ambitious approach for cardiac repair is tissue engineering in its strict sense, i.e., the generation of coherently beating $3 \mathrm{D}$ heart tissues in vitro and their transplantation onto 
the injured heart (Table 1). Since immature cardiomyocytes beat spontaneously and have the capacity to form a 3D network of communicating cells, the first steps towards forming engineered heart tissue (EHT) can be quite easily achieved (review in [92]). The incorporation of cells into a hydrogel is one of the oldest ideas in tissue engineering, which was introduced 35 years ago [93] and was applied to generate the first engineered cardiac tissues [94]. The most commonly used hydrogels are based on collagen I [87], Matrigel [95], fibrin $[88,89 \bullet \cdot, 96]$, and mixtures thereof. The principle is always similar: cells are mixed with the hydrogel and filled into a casting mold that determines the shape of the engineered tissue. Various systems have been developed to fix the remodeling tissue and provide the mechanical strain necessary for cell orientation between the fixation points. The setup ranges from Velcro-coated glass tubes [94], rings [95], Flexcell chambers [97], and mesoscopic micropost arrays [98] to newer systems in which the fixation posts serve as means to measure contractile force $[99,100]$ (overview in [48]). For cardiac repair, the hydrogel systems can be upscaled, either by employing larger casting molds [101] or assembling of several smaller elements [102]. Alternatives to the hydrogel methods are (i) seeding cardiac myocytes onto prefabricated biodegradable matrices [103, 104], (ii) repopulation of decellularized natural heart tissue $[105,106]$, or (iii) the cell-stack technique in which monolayers of cells are assembled to a 3D tissue without any scaffold [107]. The group of Shimizu and Okano built thin, but compact artificial cardiac tissues by stacking three monolayers for transplantation. HiPSC-CM sheets were transplanted onto the hearts of infarcted, immunosuppressed minipigs [91••]. In this study, the transplantation of eight sheets containing $25 \times 10^{6}$ cardiomyocytes improved left ventricular ejection fraction compared to sham (53 vs. $38 \%$ ), but the number of human cardiomyocytes remaining on the host myocardium 8 weeks after transplantation was very low, indicating that the functional improvement was independent of new muscle mass and due to a paracrine mechanism, a conclusion similarly made in many cell-therapy studies. After a further study in dogs [108], the group reported the first inman-study, in which cell sheets of autologous skeletal myoblasts were transplanted in a patient with idiopathic DCM and prolonged treatment with a left ventricular assist device [109]. Implantation of the cell sheet was associated with a decrease in brain natriuretic peptide plasma levels (marker of heart failure), increase in left ventricular ejection fraction, and removal of the assist device. While remarkable, the data have to be viewed with care because similar recovery can be seen (rarely) just after assist device implantation alone.

For our ongoing studies in this field, we have chosen to use a guinea pig model of cryo-injury MI. Human EHTs were made from hiPSC-cardiomyocytes and hiPSC-derived endothelial cells by a fibrin hydrogel method and a casting mold of a reasonable size for transplantation. After 2 weeks in culture, the rhythmically beating EHTs were sutured onto the hearts of immunosuppressed guinea pigs 7 days after the induction of large transmural cryo-infarctions. Twenty-eight days after transplantation, we observed remuscularization of the scar which went along with an improved LV-function. None of the treated animals rejected the graft or developed teratoma. Transplantation of cell-free EHTs served as a control group and did not show remuscularization nor improved cardiac function (published in abstract form [110]).

\section{Open Questions and Limitations}

There are still some major limitations, which have to be addressed before cardiac replacement therapy can finally enter the clinics. Here, we just want to highlight the ones we consider most important:

Tissue engineering approaches for cardiac repair have one problem in common - the vascularization (review in [111]). Studies on small rodent hearts did not reveal the severity of the problem we are facing by approaching therapy of the human heart which is more than two log units larger. If one linearly extrapolates the successful experiences in rats [102], a cardiac patch suitable for the repair of large MIs in humans needs to be several square centimeters in size and several millimeters in thickness, too big to be solely depending on diffusion [112]. So either we expect the patch to sufficiently grow in size by cellular proliferation or we need pre-vascularization. Different vascularization strategies are pursued. The main difference between the techniques is whether the vascularization is done in vitro or in vivo and if a biological vessel graft is used. Vascularized cardiac grafts can be produced in vivo by casting hydrogels on an AV-loop [113, 114] or multistacking of cell sheets on a vascularized area of the body [115]. For in vitro vascularization, cell sheets have been layered onto a surgically explanted and artificially perfused vascular beds [116•], or constructs are perfused through artificial channels [101, 117, 118]. Approaches using the biological grafts have the advantage that the vascular bed of the cardiac graft can be anastomosed after transplantation [114, 117]. Major disadvantages of pre-vascularization are the complexity of the procedures and the concomitant regulatory hurdles. Thus, the question how to overcome the upscaling problem for human cardiac repair remains open, and it is well possible that the simplest approach will finally be most successful.

Further limitations include developing cost-effective manufacturing processes. These manufacturing processes would need to achieve cardiomyocytes of sufficient purity, scale, potency, and viability to accommodate cardiac regenerative-based therapies for millions of patients. Even protocols with high efficiency [59•] end up with some noncardiomyocytes, possibly including pluripotent stem cells. The latter have the potential to cause teratoma in vivo. Hence, 


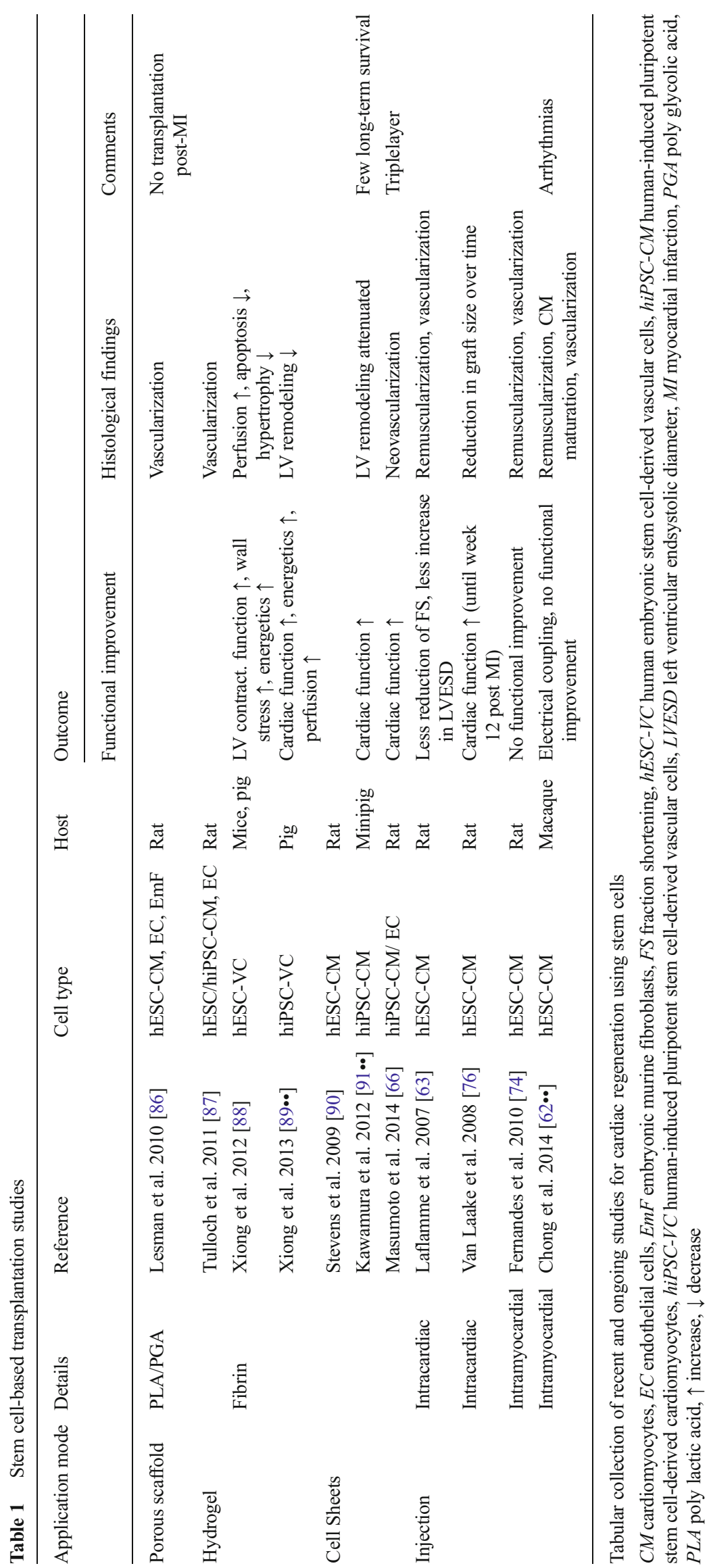


to rule out this risk, stringent quality controls of clinically applied cell batches are required beforehand, including teratoma tests in a meaningful number of animals and extensive search for pluripotent cells (suggestions for quality controls see Fig. 1). Increasing the cell purity has been approached in various ways. (i) Physical purification via Percoll-gradient proved to cause cell damage and extensive loss of viable cells [63]. (ii) Live cell sorting for cardiac-enriched surface markers
1. Quality control:

- Purity

- Vitality

- Contractility (engineered tissues)

- Karyogram

- Biomaterial formulation

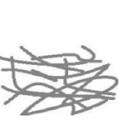

Biomaterial (e.g. fibrin, collagen I, matrigel)

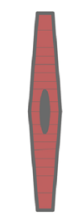

hiPS-CM

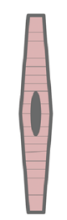

hES-CM

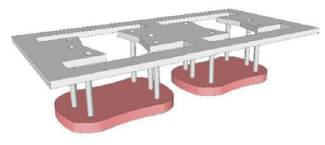

EHT

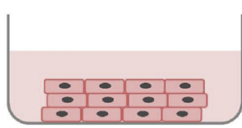

Cell sheet

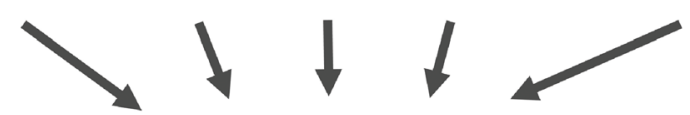

2. Animal model:

- Reproducible infarct size

- Relevant reduction of ejection fraction

- Delayed start of intervention after infarct

- Cell number / patch size

- Recipient animal (e.g. species, sex, age, drugs)

- Sham, negative controls (cell-free, non-.contractile)

- Power calculation

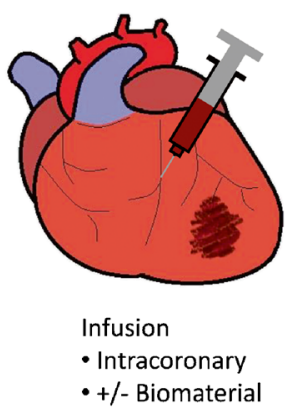

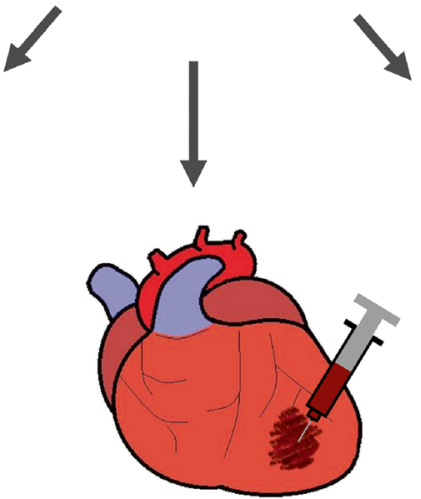

Injection

- Intramyocardial

-+/- Biomaterial

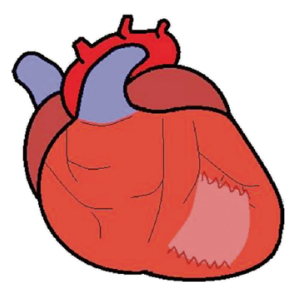

Cardiac patch

- Hydrogel-based

- Cell sheet

- Prefabricated scaffold

- Decellularized tissue

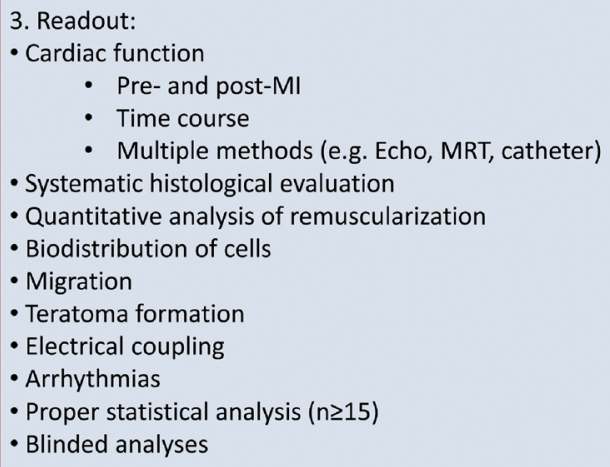

Fig. 1 Engineering cardiovascular regeneration. Schematic overview of different approaches for cardiac regeneration and suggested parameters for quality control, animal model, and readout to align animal studies and facilitate comparison (EHT engineered heart tissue, hiPSC-CM human- induced pluripotent stem cell-derived cardiomyocytes, $h E S C$-CM human embryonic stem cell-derived cardiomyocytes, $M I$ myocardial infarction) 
such as SIRP $\alpha$-positive cells [119] or fluorescent mitochondrial dyes like tetramethylrhodamine methyl ester perchlorate [120] work, but may be difficult to scale up at reasonable costs.

(iii) Culture in pure lactate-containing media enrich cardiomyocyte populations, but at the price of considerable cell loss ([121], own unpublished observation). Cellular Dynamics International (USA) and Axiogenesis AG (Germany) provide highly purified cardiomyocytes enriched by antibiotic selection (stably integrated antibiotic selection cassette). Unfortunately, the genetic modification will complicate the use in clinical studies. Without additional enrichment strategies, current differentiation protocols achieve 70-95\% cardiomyocyte purity. As such, Pluriomics (Netherlands) offers highly purified cardiomyocytes without genetic alterations. By using small molecules instead of cytokines, the production of hESC-cardiomyocytes has become much more reliable ([61]; own observation for hiPS-cardiomyocyte differentiation). Quality control including chromosomal integrity [122, 123], lack of pluripotent cells in Good Manufacturing Practice (GMP)-produced cardiomyocyte batches is mandatory for a future clinical application and could include karyograms, PCR, and teratoma formation assay.

Immune responses remain an issue. As outlined above, cells derived from autologous hiPSC should theoretically not cause immune responses, but this might not be the case [52•, 53]. If this holds true, hiPSC lose their major advantages over hESC. A possible solution is the establishment of cell banks (hESC, hPSC, hiPSC) representing the majority of the HLA spectrum in the targeted recipient population [51].

Independent of the source (hESC, hPSC, hiPSC), the maturation state of the PSC-derived cardiomyocytes is still not satisfying [124]. On the one hand, spontaneous pacemaking could be a reason for arrhythmogenesis after transplantation [62••], but it may also be an advantage by allowing the cells to survive the hypoxic environment of the host myocardium prior to vascularization and to proliferate for a while after transplantation (own unpublished data). Thus, it may not even be desirable to wait until terminal maturation before implanting or injecting PSC-derived cardiomyocytes.

So far, there is no systematic and sufficiently powered study analyzing the biodistribution of the transplanted cells. Some studies do not find cells of the graft in any other organs than the heart (e.g., [62••]), but others do [78]. The detection rate obviously depends on the sensitivity and specificity of the detection method (i.e., PCR vs. histology). In our studies with hiPSC-derived EHT in guinea pigs, we occasionally observed human DNA in organs other than the heart, suggesting that even in a tissue engineering approach with embedded cells, the latter can be washed out in vivo (own unpublished data). It seems very unlikely that the problem is smaller when (much larger numbers of) cells are simply injected into the heart. Thus, we believe that this problem has to be considered in future studies. It relates to the need for studies defining the minimal effective dose of hiPSC-CM or hiPSC-EHTs.
The occurrence of ventricular arrhythmias after transplantation may compromise the success of cardiac regeneration therapies. Clinical studies with skeletal myoblasts regularly observed transplantation-induced arrhythmias and requested implantation of intracardiac defibrillators [81]. In contrast, injection of hESC-derived cardiomyocytes into infarcted guinea pig hearts suppressed the rate of arrhythmias, likely due to the fact that most hESC-CM electromechanically coupled to the host myocardium [75]. Good coupling was also observed in the macaque study [62.•] and former rat studies with rat grafts $[102,125]$. But of note, in the macaque study, severe arrhythmias were observed in all recipients of the hESC-CM grafts. The difference to the guinea pig study remain unexplained, but could be related to the different size or impaired calcium-handling [62・•, 126].

The adequate animal model for obtaining valid preclinical data is still a matter of debate. Non-human primates like Rhesus macaques have the advantage of providing a homologous transplantation model if rhesus PSC are used. But they have also several disadvantages. Ethical (and also economic) concerns limit the number of animals for a transplantation study. Non-human primates do not tolerate large MIs, i.e., a large drop in contractile function [84], which leaves not much room for functional improvement. Another disadvantage of the primate-model is their heart size, which is eight times smaller than that of humans [77]. Larger hearts require higher cell numbers, and therefore, the true arrhythmic potential may be even underestimated as stated by Chong and colleagues $[62 \bullet \cdot]$. Other animal models such as pigs and sheep have the advantage of heart rate and size being closer to humans. Furthermore, sheep and pigs tolerate larger infarcts, and studies in these models are ethically accepted, less expensive, and logistically less cumbersome. On the other hand, iPSC from pig are not stable, precluding an autologous or allogeneic approach. The only study with hiPSC-CM on pigs was done under immunosuppression, and the survival rate of human cells was not quantified $[91 \bullet \bullet]$.

\section{Conclusion}

The exciting progress in pluripotent stem cell technologies, protocols for the differentiation of cardiomyocytes from PSC, and tissue engineering techniques have made cardiac replacement therapy a realistic scenario. Indeed, the first patients with myocardial infarction has been already treated, albeit with a very low cell number. Nevertheless, in our opinion, it is still a long road to go until cardiac repair will reach clinical routine. More studies in relevant animal models are needed that apply current guidelines of regulatory agencies for the preclinical development of cell therapies. These studies need to quantitatively address safety issues, minimal effective doses and the extent to which functional benefits can be 
accounted for by remuscularization as compared to poorly defined "paracrine effects".

Acknowledgments This work is supported by grants from the European Union (Biodesign, FP7), the German Research Foundation (DFG Es 88/12-1, DFG Ha 3/1), the German Ministry of Research [Deutsches Zentrum für Herz-Kreislauf-Forschung e.V. (German Centre for Cardiovascular Research)], and the German Heart Foundation. The data on cardiac repair cited in this article were obtained primarily by Florian Weinberger, Kaja Breckwoldt and Simon Pecha, Hamburg.

\section{Compliance with Ethics Guidelines}

Conflict of Interest Ingra Vollert reports a patent WO 2014/154704 A1 pending.

Alexandra Eder and Arne Hansen declare that they have no conflict of interest.

Thomas Eschenhagen reports a patent WO 2014/154704 A1 pending and a patent PCT WO 015529 issued.

Human and Animal Rights and Informed Consent The authors declare that in this review, they cite observations from their own ongoing unpublished studies, some of which involve studies with animal subjects. However, all of these investigations conform to the guidelines for the care and use of laboratory animals published by the United States NIH (Publication No. 85-23, revised 1985) and were approved by local German authorities (BGV, Freie und Hansestadt Hamburg: 85/12)

\section{References}

Papers of particular interest, published recently, have been highlighted as:

- Of importance

•- Of major importance

1. World Health Organziation, Fact Sheet $\mathrm{N}^{\mathrm{o}} 310$, The 10 leading causes of death in the world, updated May 2014. Acess of http:// www.who.int/mediacentre/factsheets/fs310/en/ on January 12th, 2015.

2. Kajstura J, Rota M, Cappetta D, et al. Cardiomyogenesis in the aging and failing human heart. Circulation. 2012;126:1869-81.

3. Orlic D, Kajstura J, Chimenti S, et al. Bone marrow cells regenerate infarcted myocardium. Nature. 2001;410:701-5.

4. Bergmann O, Bhardwaj RD, Bernard S, et al. Evidence for cardiomyocyte renewal in humans. Science. 2009;324:98-102.

5. Senyo SE, Steinhauser ML, Pizzimenti CL, et al. Mammalian heart renewal by pre-existing cardiomyocytes. Nature. 2013;493: 433-6.

6. Cleland JGF, Torabi A, Khan NK. Epidemiology and management of heart failure and left ventricular systolic dysfunction in the aftermath of a myocardial infarction. Heart. 2005;91 Suppl 2: ii7-13. discussion ii31, ii43-8.

7. Kirklin JK, Naftel DC, Kormos RL, et al. The Fourth INTE RMACS Annual Report: 4,000 implants and counting. J Heart Lung Transplant. 2012;31:117-26.

8. Hajjar RJ, Zsebo K, Deckelbaum L, et al. Design of a phase 1/2 trial of intracoronary administration of AAV1/SERCA2a in patients with heart failure. J Card Fail. 2008;14:355-67.

9. Jessup M, Greenberg B, Mancini D, et al. Calcium Upregulation by Percutaneous Administration of Gene Therapy in Cardiac Disease (CUPID): a phase 2 trial of intracoronary gene therapy of sarcoplasmic reticulum Ca2+-ATPase in patients with advanced heart failure. Circulation. 2011;124:304-13.

10. U.S. Department of Health and Human Services, Food and Drug Administration, Center for Biologics Evaluation and Research, Guidance for Industry, Preclinical Assessment of Investigational Cellular and Gene Therapy Products, November 2013, Access of http://www.fda.gov/downloads/BiologicsBloodVaccines/ GuidanceComplianceRegulatoryInformation/Guidances/ CellularandGeneTherapy/UCM376521.pdf on January 12th, 2015.

11. Garbern JC, Lee RT. Cardiac stem cell therapy and the promise of heart regeneration. Cell Stem Cell. 2013;12:689-98.

12. Matar AA, Chong JJ. Stem cell therapy for cardiac dysfunction. Springerplus. 2014;3:440.

13. Murry CE, Soonpaa MH, Reinecke H, et al. Haematopoietic stem cells do not transdifferentiate into cardiac myocytes in myocardial infarcts. Nature. 2004;428:664-8.

14. Chien KR. Stem cells: lost in translation. Nature. 2004;428:607-8.

15. Nowbar AN, Mielewczik M, Karavassilis M, et al. Discrepancies in autologous bone marrow stem cell trials and enhancement of ejection fraction (DAMASCENE): weighted regression and metaanalysis. BMJ. 2014;348:g2688.

16. Hofmann M, Wollert KC, Meyer GP, et al. Monitoring of bone marrow cell homing into the infarcted human myocardium. Circulation. 2005;111:2198-202.

17. Terrovitis JV, Smith RR, Marbán E. Assessment and optimization of cell engraftment after transplantation into the heart. Circ Res. 2010;106:479-94.

18. Urbich C, De Souza AI, Rossig L, et al. Proteomic characterization of human early pro-angiogenic cells. J Mol Cell Cardiol. 2011;50:333-6.

19. Badorff C. Transdifferentiation of blood-derived human adult endothelial progenitor cells Into functionally active cardiomyocytes. Circulation. 2003;107:1024-32.

20. Grunewald M, Avraham I, Dor Y, et al. VEGF-induced adult neovascularization: recruitment, retention, and role of accessory cells. Cell. 2006;124:175-89.

21. Simper D, Mayr U, Urbich C, et al. Comparative proteomics profiling reveals role of smooth muscle progenitors in extracellular matrix production. Arterioscler Thromb Vasc Biol. 2010;30: 1325-32.

22. Ziegelhoeffer T, Fernandez B, Kostin S, et al. Bone marrowderived cells do not incorporate into the adult growing vasculature. Circ Res. 2004;94:230-8.

23. Bartunek J, Behfar A, Dolatabadi D, et al. Cardiopoietic stem cell therapy in heart failure: the C-CURE (Cardiopoietic stem Cell therapy in heart failURE) multicenter randomized trial with lineage-specified biologics. J Am Coll Cardiol. 2013;61:2329-38.

24. Otto WR, Wright NA. Mesenchymal stem cells: from experiment to clinic. Fibrogenesis Tissue Repair. 2011;4:20.

25. Chugh AR, Beache GM, Loughran JH, et al. Administration of cardiac stem cells in patients with ischemic cardiomyopathy: the SCIPIO trial: surgical aspects and interim analysis of myocardial function and viability by magnetic resonance. Circulation. 2012;126:S54-64.

26. Van Berlo JH, Kanisicak O, Maillet M, et al. C-Kit+ cells minimally contribute cardiomyocytes to the heart. Nature. 2014;509: 337-41.

27. Bolli R, Chugh AR, D'Amario D, et al. Cardiac stem cells in patients with ischaemic cardiomyopathy (SCIPIO): initial results of a randomised phase 1 trial. Lancet. 2011;378: 1847-57.

28. The Lancet Editors. Expression of concern: the SCIPIO trial. Lancet 2014;383:1279. 
29. Messina E, De Angelis L, Frati G, et al. Isolation and expansion of adult cardiac stem cells from human and murine heart. Circ Res. 2004;95:911-21.

30. Malliaras K, Makkar RR, Smith RR, et al. Intracoronary cardiosphere-derived cells after myocardial infarction: evidence of therapeutic regeneration in the final 1-year results of the CADUCEUS trial (CArdiosphere-Derived aUtologous stem CElls to reverse ventricUlar dySfunction). J Am Coll Cardiol. 2014;63:110-22.

31. Petsche Connell J, Camci-Unal G, Khademhosseini A, et al. Amniotic fluid-derived stem cells for cardiovascular tissue engineering applications. Tissue Eng Part B Rev. 2013;19:368-79.

32. Zhang W, Liu X, Yang L, et al. Wharton's jelly-derived mesenchymal stem cells promote myocardial regeneration and cardiac repair after miniswine acute myocardial infarction. Coron Artery Dis. 2013;24:549-58.

33. Reichman S, Terray A, Slembrouck A, et al. From confluent human iPS cells to self-forming neural retina and retinal pigmented epithelium. Proc Natl Acad Sci U S A. 2014;111:8518-23.

34. Yoshida Y, Yamanaka S. iPS cells: a source of cardiac regeneration. J Mol Cell Cardiol. 2011;50:327-32.

35. Thomson JA, Itskovitz-Eldor J, Shapiro SS, et al. Embryonic stem cell lines derived from human blastocysts. Science. 1998;282: $1145-7$

36. Schwartz SD, Hubschman JP, Heilwell G, et al. Embryonic stem cell trials for macular degeneration: a preliminary report. Lancet. 2012;379:713-20.

37. Schwartz SD, Regillo CD, Lam BL, et al. Human embryonic stem cell-derived retinal pigment epithelium in patients with age-related macular degeneration and Stargardt's macular dystrophy: followup of two open-label phase 1/2 studies. Lancet. 2015;385:509-16. early online publication.

38. Simard LC. Total malignant teratoma of the human ovary, of probable parthenogenetic origin. Rev Can Biol. 1950;9:344-67.

39. Didié M, Christalla P, Rubart M, et al. Parthenogenetic stem cells for tissue-engineered heart repair. J Clin Invest. 2013;123:128598.

40. Revazova ES, Turovets NA, Kochetkova OD, et al. Patientspecific stem cell lines derived from human parthenogenetic blastocysts. Cloning Stem Cells. 2007;9:432-49.

41. Takahashi K, Yamanaka S. Induction of pluripotent stem cells from mouse embryonic and adult fibroblast cultures by defined factors. Cell. 2006;126:663-76.

42. Vitale AM, Wolvetang E, Mackay-Sim A. Induced pluripotent stem cells: a new technology to study human diseases. Int J Biochem Cell Biol. 2011;43:843-6.

43. Macarthur CC, Fontes A, Ravinder N, et al. Generation of humaninduced pluripotent stem cells by a nonintegrating RNA Sendai virus vector in feeder-free or xeno-free conditions. Stem Cells Int. 2012;2012:564612. The authors describe a method for the generation of hiPSC without the use of integrating virus.

44. Warren L, Manos PD, Ahfeldt T, et al. Highly efficient reprogramming to pluripotency and directed differentiation of human cells with synthetic modified mRNA. Cell Stem Cell. 2010;7:618-30.

45. Zhou H, Wu S, Joo JY, et al. Generation of induced pluripotent stem cells using recombinant proteins. Cell Stem Cell. 2009;4: $381-4$.

46. Huangfu D, Maehr R, Guo W, et al. Induction of pluripotent stem cells by defined factors is greatly improved by small-molecule compounds. Nat Biotechnol. 2008;26:795-7.

47. Shi Y, Do JT, Desponts C, et al. A combined chemical and genetic approach for the generation of induced pluripotent stem cells. Cell Stem Cell. 2008;2:525-8.
48. Eschenhagen T, Eder A, Vollert I, et al. Physiological aspects of cardiac tissue engineering. Am J Physiol Heart Circ Physiol. 2012;303:H133-43.

49. De Wert G, Mummery C. Human embryonic stem cells: research, ethics and policy. Hum Reprod. 2003;18:672-82.

50. De Vries RBM, Oerlemans A, Trommelmans L, et al. Ethical aspects of tissue engineering: a review. Tissue Eng Part B Rev. 2008; $14: 367-75$

51. Taylor CJ, Bolton EM, Pocock S, et al. Banking on human embryonic stem cells: estimating the number of donor cell lines needed for HLA matching. Lancet. 2005;366:2019-25.

52. Zhao T, Zhang Z-N, Rong Z, et al. Immunogenicity of induced pluripotent stem cells. Nature. 2011;474:212-5. This paper discusses the unexpected immunogenic potential of iPSC.

53. Fu X. The immunogenicity of cells derived from induced pluripotent stem cells. Cell Mol Immunol. 2014;11:14-6.

54. Shi Y, Desponts C, Do JT, et al. Induction of pluripotent stem cells from mouse embryonic fibroblasts by Oct4 and Klf4 with smallmolecule compounds. Cell Stem Cell. 2008;3:568-74.

55. Martins-Taylor K, Xu R-H. Concise review: genomic stability of human induced pluripotent stem cells. Stem Cells. 2012;30:22-7.

56. Salmikangas P, Flory E, Reinhardt J, et al. Regulatory requirements for clinical trial and marketing authorisation application for cellbased medicinal products. Bundesgesundheitsblatt Gesundheitsforschung Gesundheitsschutz. 2010;53:24-9.

57. Doetschman TC, Eistetter H, Katz M. The in vitro development of blastocyst-derived embryonic stem cell lines: formation of visceral yolk sac, blood islands and myocardium. J Embryol Exp Morphol. 1985;87:27-45.

58. Kehat I, Kenyagin-Karsenti D, Snir M, et al. Human embryonic stem cells can differentiate into myocytes with structural and functional properties of cardiomyocytes. J Clin Invest. 2001;108:40714.

59. Burridge PW, Matsa E, Shukla P, et al. Chemically defined generation of human cardiomyocytes. Nat Methods. 2014;11: 855-60. This protocol nicely shows the differentiation of cardiomyocytes with high purity and efficiency.

60. Chen G, Gulbranson DR, Hou Z, et al. Chemically defined conditions for human iPSC derivation and culture. Nat Methods. 2011;8:424-9.

61. Lian X, Zhang J, Azarin SM, et al. Directed cardiomyocyte differentiation from human pluripotent stem cells by modulating $\mathrm{Wnt} / \beta$-catenin signaling under fully defined conditions. Nat Protoc. 2013;8:162-75.

62.• Chong JJH, Yang X, Don CW, et al. Human embryonic stem cellderived cardiomyocytes regenerate non-human primate hearts. Nature. 2014;510:273-7. This small study describes the regeneration of infarcted macaques hearts by injection of human embryonic stem cell-derived cardiomyocytes.

63. Laflamme MA, Chen KY, Naumova AV, et al. Cardiomyocytes derived from human embryonic stem cells in pro-survival factors enhance function of infarcted rat hearts. Nat Biotechnol. 2007;25: 1015-24.

64. Kattman SJ, Witty AD, Gagliardi M, et al. Stage-specific optimization of activin/nodal and BMP signaling promotes cardiac differentiation of mouse and human pluripotent stem cell lines. Cell Stem Cell. 2011;8:228-40.

65. Keller G, Snodgrass HR. Human embryonic stem cells: the future is now. Nat Med. 1999;5:151-2.

66. Masumoto H, Ikuno T, Takeda M, et al. Human iPS cellengineered cardiac tissue sheets with cardiomyocytes and vascular cells for cardiac regeneration. Sci Rep. 2014;4:6716.

67. Mummery CL, Ward-van Oostwaard D, Doevendans P. Differentiation of human embryonic stem cells to cardiomyocytes 
- Role of coculture with visceral endoderm-like cells. Circulation. 2002;107:2733-2740.

68. Ng ES, Davis RP, Azzola L, et al. Forced aggregation of defined numbers of human embryonic stem cells into embryoid bodies fosters robust, reproducible hematopoietic differentiation. Blood. 2005;106:1601-3.

69. Itskovitz-Eldor J, Schuldiner M, Karsenti D, et al. Differentiation of human embryonic stem cells into embryoid bodies compromising the three embryonic germ layers. Mol Med. 2000;6:88-95.

70. Niebruegge $\mathrm{S}$, Nehring A, Bär $\mathrm{H}$, et al. Cardiomyocyte production in mass suspension culture: embryonic stem cells as a source for great amounts of functional cardiomyocytes. Tissue Eng Part A. 2008;14:1591-601.

71. Mummery CL, Zhang J, Ng ES, et al. Differentiation of human embryonic stem cells and induced pluripotent stem cells to cardiomyocytes: a methods overview. Circ Res. 2012;111:344 58.

72. Xu C, Police S, Hassanipour M, et al. Efficient generation and cryopreservation of cardiomyocytes derived from human embryonic stem cells. Regen Med. 2011;6:53-66. This protocol demonstrates the possibility to cryoconservate differentiated cardiomyocytes for high cell number applications.

73. Reardon S, Cyranoski D. Japan stem-cell trial stirs envy. Nature. 2014;513:287-8.

74. Fernandes S, Naumova AV, Zhu WZ, et al. hESC-derived cardiomyocytes engraft but do not alter cardiac remodeling after chronic infarction in rats. J Mol Cell Cardiol. 2010;49:941-9.

75. Shiba Y, Fernandes S, Zhu W-Z, et al. Human ES-cell-derived cardiomyocytes electrically couple and suppress arrhythmias in injured hearts. Nature. 2012;489:322-5.

76. Van Laake LW, Passier R, Doevendans PA, et al. Human embryonic stem cell-derived cardiomyocytes and cardiac repair in rodents. Circ Res. 2008;102:1008-10.

77. Anderson ME, Goldhaber J, Houser SR, et al. Embryonic stem cell-derived cardiac myocytes are not ready for human trials. Circ Res. 2014;115:335-8.

78. Dow J, Simkhovich BZ, Kedes L, et al. Washout of transplanted cells from the heart: a potential new hurdle for cell transplantation therapy. Cardiovasc Res. 2005;67:301-7.

79. Fernandes S, Kuklok S, McGonigle J, et al. Synthetic matrices to serve as niches for muscle cell transplantation. Cells Tissues Organs. 2012;195:48-59.

80. Segers VFM, Lee RT. Biomaterials to enhance stem cell function in the heart. Circ Res. 2011;109:910-22.

81. Menasché $\mathrm{P}$, Alfieri $\mathrm{O}$, Janssens $\mathrm{S}$, et al. The myoblast autologous grafting in ischemic cardiomyopathy (MAGIC) trial: first randomized placebo-controlled study of myoblast transplantation. Circulation. 2008;117:1189-200.

82. Reinecke H, Macdonald GH, Hauschka SD, et al. Electromechanical coupling between skeletal and cardiac muscle: implications for infarct repair. J Cell Biol. 2000;149:731-40.

83. Hamdi H, Furuta A, Bellamy V, et al. Cell delivery: intramyocardial injections or epicardial deposition? A head-to-head comparison. Ann Thorac Surg. 2009;87:1196-203.

84. Bel A, Planat-Bernard V, Saito A, et al. Composite cell sheets: a further step toward safe and effective myocardial regeneration by cardiac progenitors derived from embryonic stem cells. Circulation. 2010;122:S118-23.

85. Menasché P, Vanneaux V, Fabreguettes J-R, et al. Towards a clinical use of human embryonic stem cell-derived cardiac progenitors: a translational experience. Eur Heart J. 2014;36(12):743-50.

86. Lesman A, Habib M, Caspi O, et al. Transplantation of a tissueengineered human vascularized cardiac muscle. Tissue Eng Part A. $2010 ; 16: 115-25$.
87. Tulloch NL, Muskheli V, Razumova MV, et al. Growth of engineered human myocardium with mechanical loading and vascular coculture. Circ Res. 2011;109:47-59.

88. Xiong Q, Ye L, Zhang P, et al. Bioenergetic and functional consequences of cellular therapy: activation of endogenous cardiovascular progenitor cells. Circ Res. 2012;111:455-68.

89.• Xiong Q, Ye L, Zhang P, et al. Functional consequences of human induced pluripotent stem cell therapy: myocardial ATP turnover rate in the in vivo swine heart with postinfarction remodeling. Circulation. 2013;127:997-1008. This paper reports the functional consequences of tissue engineered hiPSC-grafts on the energetics of the infarcted pig heart.

90. Stevens KR, Kreutziger KL, Dupras SK, et al. Physiological function and transplantation of scaffold-free and vascularized human cardiac muscle tissue. Proc Natl Acad Sci U S A. 2009;106: $16568-73$.

91.• Kawamura M, Miyagawa S, Miki K, et al. Feasibility, safety, and therapeutic efficacy of human induced pluripotent stem cell-derived cardiomyocyte sheets in a porcine ischemic cardiomyopathy model. Circulation. 2012;126:S29-37. These authors describe the transplantation of in vitro generated cell sheets onto hearts of pigs suffering from ischemic cardiomyopathy.

92. Hirt MN, Hansen A, Eschenhagen T. Cardiac tissue engineering: state of the art. Circ Res. 2014;114:354-67.

93. Weinberg CB, Bell E. A blood vessel model constructed from collagen and cultured vascular cells. Science. 1986;231:397-400.

94. Eschenhagen T, Fink C, Remmers U, et al. Three-dimensional reconstitution of embryonic cardiomyocytes in a collagen matrix: a new heart muscle model system. FASEB J. 1997;11:683-94.

95. Zimmermann WH, Schneiderbanger K, Schubert P, et al. Tissue engineering of a differentiated cardiac muscle construct. Circ Res. 2002;90:223-30.

96. Wei HJ, Chen CH, Lee WY, et al. Bioengineered cardiac patch constructed from multilayered mesenchymal stem cells for myocardial repair. Biomaterials. 2008;29:3547-56.

97. De Lange WJ, Hegge LF, Grimes AC, et al. Neonatal mousederived engineered cardiac tissue: a novel model system for studying genetic heart disease. Circ Res. 2011;109:8-19.

98. Bian W, Liau B, Badie N, et al. Mesoscopic hydrogel molding to control the 3D geometry of bioartificial muscle tissues. Nat Protoc. 2009; 4:1522-34.

99. Hansen A, Eder A, Bönstrup M, et al. Development of a drug screening platform based on engineered heart tissue. Circ Res. 2010;107:35-44

100. Boudou T, Legant WR, Mu A, et al. A microfabricated platform to measure and manipulate the mechanics of engineered cardiac microtissues. Tissue Eng Part A. 2012;18:9-10.

101. Vollert I, Seiffert M, Bachmair J, et al. In vitro perfusion of engineered heart tissue through endothelialized channels. Tissue Eng Part A. 2014;20:854-63.

102. Zimmermann WH, Melnychenko I, Wasmeier G, et al. Engineered heart tissue grafts improve systolic and diastolic function in infarcted rat hearts. Nat Med. 2006;12:452-8.

103. Radisic M, Marsano A, Maidhof R, et al. Cardiac tissue engineering using perfusion bioreactor systems. Nat Protoc. 2008;3:71938.

104. Marsano A, Maidhof R, Luo J, et al. The effect of controlled expression of VEGF by transduced myoblasts in a cardiac patch on vascularization in a mouse model of myocardial infarction. Biomaterials. 2013;34:393-401.

105. Ott HC, Matthiesen TS, Goh SK, et al. Perfusion-decellularized matrix: using nature's platform to engineer a bioartificial heart. Nat Med. 2008;14:213-21.

106. Godier-Furnémont AFG, Martens TP, Koeckert MS, et al. Composite scaffold provides a cell delivery platform for cardiovascular repair. Proc Natl Acad Sci U S A. 2011;108:7974-9. 
107. Shimizu T, Yamato M, Isoi Y, et al. Fabrication of pulsatile cardiac tissue grafts using a novel 3-dimensional cell sheet manipulation technique and temperature-responsive cell culture surfaces. Circ Res. 2002;90:e40.

108. Hata H, Matsumiya G, Miyagawa S, et al. Grafted skeletal myoblast sheets attenuate myocardial remodeling in pacing-induced canine heart failure model. J Thorac Cardiovasc Surg. 2006;132: 918-24.

109. Sawa Y, Miyagawa S, Sakaguchi T, et al. Tissue engineered myoblast sheets improved cardiac function sufficiently to discontinue LVAS in a patient with DCM: report of a case. Surg Today. 2012;42:181-4.

110. Breckwoldt K, Weinberger F, Pecha S, et al. Human induced pluripotent stem cells for tissue-engineered cardiac repair [Abstract]. Cardiovasc Res. 2014;103:52-3.

111. Montgomery M, Zhang B, Radisic M. Cardiac tissue vascularization: from angiogenesis to microfluidic blood vessels. J Cardiovasc Pharmacol Ther. 2014;19:382-93.

112. Lovett M, Lee K, Edwards A, et al. Vascularization strategies for tissue engineering. Tissue Eng Part B Rev. 2009;15:353-70.

113. Morritt AN, Bortolotto SK, Dilley RJ, et al. Cardiac tissue engineering in an in vivo vascularized chamber. Circulation. 2007;115: 353-60.

114. Tee R, Morrison WA, Dusting GJ, et al. Transplantation of engineered cardiac muscle flaps in syngeneic rats. Tissue Eng Part A. 2012;18:1992-9.

115. Shimizu T, Sekine H, Yang J, et al. Polysurgery of cell sheet grafts overcomes diffusion limits to produce thick, vascularized myocardial tissues. FASEB J. 2006;20:708-10.

116. Sekine H, Shimizu T, Sakaguchi K, et al. In vitro fabrication of functional three-dimensional tissues with perfusable blood vessels.
Nat Commun. 2013;4:1399-409. This group reports the feasability to transplant in vitro prevascularized tissues.

117. Sakaguchi K, Shimizu T, Horaguchi S, et al. In vitro engineering of vascularized tissue surrogates. Sci Rep. 2013;3:1316-23.

118. Maidhof R, Tandon N, Lee EJ, et al. Biomimetic perfusion and electrical stimulation applied in concert improved the assembly of engineered cardiac tissue. J Tissue Eng Regen Med. 2012;6:e12-23.

119. Dubois NC, Craft AM, Sharma P, et al. SIRPA is a specific cellsurface marker for isolating cardiomyocytes derived from human pluripotent stem cells. Nat Biotechnol. 2011;29:1011-8.

120. Hattori F, Chen H, Yamashita H, et al. Nongenetic method for purifying stem cell-derived cardiomyocytes. Nat Methods. 2010;7:61-6.

121. Tohyama S, Hattori F, Sano M, et al. Distinct metabolic flow enables large-scale purification of mouse and human pluripotent stem cell-derived cardiomyocytes. Cell Stem Cell. 2013;12:127-37.

122. Gore A, Li Z, Fung H-L, et al. Somatic coding mutations in human induced pluripotent stem cells. Nature. 2011;471:63-7.

123. Hussein SM, Batada NN, Vuoristo S, et al. Copy number variation and selection during reprogramming to pluripotency. Nature. 2011;471:58-62.

124. Yang X, Pabon L, Murry CE. Engineering adolescence: maturation of human pluripotent stem cell-derived cardiomyocytes. Circ Res. 2014;114:511-23.

125. Furuta A, Miyoshi S, Itabashi Y, et al. Pulsatile cardiac tissue grafts using a novel three-dimensional cell sheet manipulation technique functionally integrates with the host heart, in vivo. Circ Res. 2006;98:705-12.

126. Clusin WT. Mechanisms of calcium transient and action potential alternans in cardiac cells and tissues. Am J Physiol Heart Circ Physiol. 2008;294:H1-10. 